\title{
Managing severe cancer pain: the role of transdermal buprenorphine: a systematic review
}

This article was published in the following Dove Press journal:

Therapeutics and Clinical Risk Management

3 September 2009

Number of times this article has been viewed

\section{S Deandrea ${ }^{1,2}$ \\ O Corli' \\ I Moschetti ${ }^{3}$ \\ G Apolone'}

'Center for the Evaluation and Research on Pain (CERP), Istituto di Ricerche Farmacologiche "Mario Negri", Milan, Italy; ${ }^{2}$ Istituto di Statistica Medica e Biometria "GA Maccacaro", Università degli studi di Milano, Milan, Italy; ${ }^{3}$ Italian Cochrane Center, Istituto di Ricerche Farmacologiche "Mario Negri", Milan, Italy
Correspondence: Giovanni Apolone Center for the Evaluation and Research on Pain (CERP), Istituto di Ricerche Farmacologiche "Mario Negri”, Via La Masa 19, 20156 Milan Italy Tel +3902 390I4-5I5

Fax +3902 33200-231

Email apolone@marionegri.it

\begin{abstract}
Pain is a frequent and important symptom in cancer patients. Among the available strong opioids, transdermal buprenorphine has been licensed in Europe since 2002, and results from a few clinical studies suggest that it may be a good alternative to the other oral or transdermal opioids. To assess the best available evidence on its efficacy and safety, we carried out a systematic literature review with the aim of pooling relevant studies. We identified 19 eligible papers describing 12 clinical studies ( 6 randomized controlled trials and 6 observational prospective studies), including a total of about 5000 cancer patients. Given the poor quality of reports and the heterogeneity of methods and outcomes, pooling was not feasible as the type of data was not appropriate for combining the results statistically. A meta-analysis based on individual data is ongoing in the context of the Cochrane Collaboration. In conclusion, although the narrative appraisal of each study suggests a positive risk benefit profile, well designed and statistically powered controlled clinical trials are needed to confirm this preliminary evidence.
\end{abstract}

Keywords: systematic review, transdermal buprenorphine, cancer pain

\section{Introduction}

Advances in prevention, diagnosis, and therapy have extended the life expectancy of cancer patients, but improvement in the survival is still disappointing for most common tumors, mostly when the disease is diagnosed at advanced or metastatic stages. Despite the availability of new and innovative anti-cancer drugs, metastatic patients are indeed unlikely to have important benefit from these treatments either in terms of quantity and quality of life. For most of these patients, the later part of their lives is impaired by pain, fatigue, depression, and other symptoms related to the disease and treatments, which become prominent contributors to suffering. Pain, in particular, is one of the most important problems. Most patients with advanced or metastatic cancer experience pain during their life ${ }^{1,2}$ and despite effective treatments being available, undertreatment has been documented in nearly one of two patients with cancer pain, with a few differences according to geographical, economic, and cultural factors. ${ }^{3}$ The use of analgesic pharmacotherapy is the mainstay of all guidelines on pain management which are available since 1986. ${ }^{4-7}$ The World Health Organization (WHO) suggested that the choice of analgesics should be based on pain intensity, and not simply on its etiology; the preferred route of administration should be oral, for drugs ranging from paracetamol and NSAID to strong opioids, morphine being the first choice. ${ }^{4}$ Since then, a broad spectrum of analgesics has become available, such as morphine, methadone, hydromorphone, oxycodone, fentanyl, and buprenorphine, which have been shown

submit your manuscript $\mid$ www.dovepress.con 
to be effective in treating moderate to severe cancer-related pain. In addition to the traditional analgesics that are deliverable orally or parenterally, a few transdermal delivery systems (TDS) containing fentanyl or buprenorphine have been introduced onto the market, suggesting a potential for improvement in view of their advantages over the oral and parental routes, in terms of non-invasiveness and slow and continuous release of the compound. A recent review has pointed out the advantages and disadvantages of available TDS for cancer pain, focusing on the problem of transdermal dosing conversion. ${ }^{8}$ Another very recent review updated the pharmacological properties of transdermal buprenorphine with a focus on its ceiling effect, ${ }^{9}$ and also qualitatively summarized the clinical efficacy and tolerability of TDS containing buprenorphine, using results from clinical studies including cancer patients, as primary evidence. As this work combined the early and late randomized placebo and comparative trials with retrospective and prospective studies, it was difficult to obtain an overall quantitative estimate of the yield of TDS containing buprenorphine in terms of efficacy and safety.

Our paper is based on a systematic review of published literature with the aim of assessing the best available evidence for the effect of TDS containing buprenorphine in chronic cancer pain. We have searched, identified, appraised, selected, and integrated all relevant publications on this topic and attempted to combine statistically the valid studies. The results and comments are presented according to the study design (randomized clinical trials vs observational studies) and are based on 19 papers reporting data from 12 prospective studies involving more than 5000 patients.

\section{Materials and Methods Synthetic profile of buprenorphine}

Excellent profiles of the pre-clinical and clinical pharmacology of buprenorphine have been reported elsewhere. ${ }^{9-11}$

Briefly, buprenorphine is a semi-synthetic compound derived from tebaine, a natural opium alkaloid, which is structurally similar to morphine, even if several molecular differences confer a higher lipophilicity and a higher pharmacological potency.

Pharmacokinetically, buprenorphine shows very low bioavailability (about 15\%) after oral administration, ${ }^{12,13}$ because of an intense metabolic degradation at the intestinal and hepatic level (first pass). After transdermal administration, the plasma concentration remains more or less steady as a consequence of continuous delivery of the drug. A very high percentage of available buprenorphine is strongly bound to plasma proteins, ${ }^{14}$ and only the unbound fraction that consists of $3 \%$ to $5 \%$ of the total plasma buprenorphine may cross the blood-brain barrier. Transit across the blood-brain barrier is regulated by several factors, the most important being the free fraction of the drug, and lipophilicity. Among the opioids, buprenorphine has an intermediate to high lipophilic property. Once buprenorphine has crossed the blood-brain barrier, it must reach its biological target, the opioids receptors (ORs). Buprenorphine presents a high selectivity for the MOR ( $\mu$-ORs). In an in vitro study, ${ }^{15}$ the $K i$ values of buprenorphine were 0.08 for the MOR, 0.11 for the KOR, and 0.42 for the DOR. For pharmacological efficacy, buprenorphine presents $60 \%$ to $65 \%$ with respect to MOR (partial agonist). ${ }^{16-22}$ These results confirm that the analgesic activity of buprenorphine is mainly mediated by MOR; its partial agonist action reflects the potential existence of a ceiling effect that, in clinical practice, has been estimated to be about 15 to $25 \mathrm{mg}$ daily, ${ }^{23}$ a dosage that may not be compatible with the doses usually prescribed in clinical practice.

In terms of pharmacokinetics, two different metabolic pathways have been observed to work in parallel: the first consists of N-dealkylization by means of CYP3A4, and the second produces three glycuronized compounds. The first metabolic pathway generates nor-buprenorphine, the only molecule having some biological activity. Buprenorphine is eliminated through two routes: unchanged molecules are excreted mainly via the biliary system, whereas metabolites are eliminated via renal excretion, but metabolite accumulation is of minimal importance given that these agents are substantially inactive substances. ${ }^{24}$ For these reasons buprenorphine may be considered as a safe opioid in cases of reduced renal function, which is a frequent clinical condition in cancer patients, especially in the far advanced phase. ${ }^{9}$

\section{Transdermal buprenorphine in pain management}

Buprenorphine was first synthesized in the late 1960, and introduced in clinical practice for parenteral and sublingual (SL) administration in 1978 and 1981, respectively. In the late 1990s, it was introduced as a transdermal formulation, contained in a matrix patch that can be applied to the skin for a duration of up to 4 days, which was indicated for moderate to severe cancer and chronic pain unrelated to cancer. The continuous release from the matrix across the skin and then into the systemic circulation is regulated mainly by the concentration gradient across the skin and the patch. ${ }^{25}$ In the matrix patch, the drug is an integral part of the polymer structure, 
making the delivery system more robust than the reservoir patch. This feature prevents "dose-dumping" and potential overdosing either intentionally or unintentionally, as damaging the patch does not interfere with the controlled release of medication. TDS containing buprenorphine is available with release rates of $35,52.5$, and $70 \mu \mathrm{g} /$ hour $\left(\right.$ Transtec $\left.^{\circledR}\right)$ that correspond to $0.8,1.2$, and $1.6 \mathrm{mg} /$ day of buprenorphine or 60,90 , and $120 \mathrm{mg}$ /day equivalent of oral morphine, respectively. ${ }^{25,26}$ Recently, low-dose patches ( 5 to $20 \mu \mathrm{g}$ /hour released for 7 days) have been marketed in a few countries. ${ }^{26}$

Transtec $^{\circledR}$ has been available since 2002 in 18 European countries including Russia and three South American countries.

\section{Search strategy and study selection}

MEDLINE (from 1966 to April 2009), EMBASE, and the Cochrane Library were searched, and only papers written in English were taken into account for data extraction; the main search terms were: 'pain', 'neoplasms', 'buprenorphine', 'transdermal', and 'randomized controlled trial' (RCT), as well as combinations of these terms. The complete search strategy can be obtained from the authors on request. References in the published articles, reviews, meta-analyses, and relevant organization websites were checked. No systematic attempt was made to identify unpublished studies.

\section{Data extraction and synthesis}

The eligibility assessment of the titles and abstracts was performed in a standardized manner by one reviewer (SD). Two reviewers (SD and GA) independently screened the full papers. Disagreements were resolved by discussion and consensus. Details of the study design, participants, inclusion criteria, clinical setting, study duration, definition of outcomes and endpoints, and results were recorded and summarized. Given the heterogeneity of the studies and the difficulty of extracting quantitative disaggregated information from each study, we undertook a narrative synthesis of each study. Eligible studies were then grouped based on the study design (randomized vs observational). Data from the studies reporting the use of standardized measures of pain intensity were grouped, described, and integrated. In this case, an attempt to summarize the results of the studies reporting the use of standardized measures of pain intensity has been attempted using appropriate statistical methods. ${ }^{27}$

\section{Results}

The search of MEDLINE and EMBASE with the review of titles and abstracts, integrated by scanning the references and consulting experts in the field, yielded 27 relevant articles. Four articles were excluded because they were published as abstracts and/or full text was not available, and the other four were excluded because they were written in languages other than English. Figure 1 presents a flowchart of manuscript selection.

The main characteristics of the remaining 19 papers $^{28-46}$ are reported in Table 1. The 19 published articles described 16 different studies: Radbruch ${ }^{29}$ presented the aggregated data from Bohme, ${ }^{28}$ Sittl, ${ }^{31}$ and Sorge $;{ }^{32}$ Evans reported efficacy and safety data by pooling the 3 placebo-controlled RCTs $;{ }^{25}$ and Radbruch ${ }^{30}$ and Apolone ${ }^{35}$ reported the preliminary information later published by Griessinger ${ }^{33}$ and Apolone, ${ }^{46}$ respectively. Nine were clinical trials ${ }^{28,31,32,37,39-42,44}$ and 7 were observational (non-intervention) studies. ${ }^{33,34,36,38,43,45,46}$

Most of the papers reported data from a mixed population including both cancer and non-cancer patients (12/19).

Three experimental studies were subsequently excluded because they were early-phase feasibility trials: a rotation feasibility trial describing cross-over administration of two drugs, ${ }^{41}$ a pilot study describing the effect of pre-planned rotation administration of several drugs,${ }^{39}$ and a dose escalation administration trial. ${ }^{37}$ The characteristics of the remaining 6 studies, ${ }^{28,31,32,40,42,44}$ involving 499 cancer patients (range 9 to 189 ) are reported in Table $2 \mathrm{~A}$.

One observational study was also excluded, because it was focused on assessing the effect of buprenorphine TDS across pre-planned age groups, to test its effectiveness in a special population: ${ }^{43}$ the characteristics of the remaining 6 studies (4599 cancer patients, range 6 to 3690) are reported in Table $2 \mathrm{~B}$.

\section{RCTs}

Six RCTs were available for analysis and discussion. Details of the papers and the studies are summarized in Tables $2 \mathrm{~A}$ and 3. Studies may be classified into 3 types: 3 preliminary pivotal studies comparing TDS buprenorphine vs placebo, 2 testing different schedules and a maintenance regimen, respectively, and 1 comparative trial vs morphine.

The first Phase III studies were 3 multicenter, randomized, double-blind clinical trials vs placebo (Bohme, ${ }^{28} \mathrm{Sittl}^{31}$ Sorge $)^{32}$ in patients with chronic cancer and non-cancer pain, initiated and sponsored by the industry marketing in Europe the drug under evaluation. In the first and the third study, only patients whose pain was satisfactorily relieved after a run-in phase with buprenorphine SL were randomized. In the study by Sorge, ${ }^{32}$ only $35 \mu \mathrm{g} /$ hour dose strength was allowed; the 3 dose strengths $(35,52.5$, and $70 \mu \mathrm{g} /$ hour $)$ 


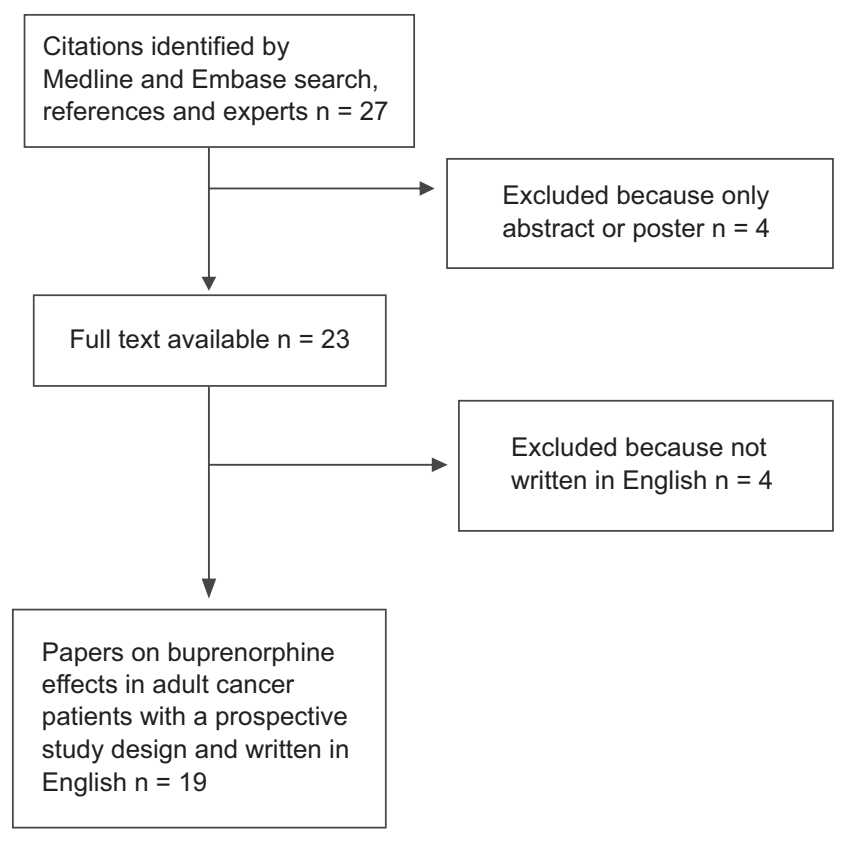

Figure I Flowchart of manuscript selection.

were used by Bohme ${ }^{28}$ and Sittl. ${ }^{31}$ In the first 2 studies, the primary outcome was the responder's status defined as 'patients whose pain relief was at least satisfactory at all determination points (excluding the final examination) and who took a mean of $0.2 \mathrm{mg} /$ day or less of SL buprenorphine on days 7-12' (Bohme) $)^{28}$ and 'any patient who required no more than $1 \mathrm{SL}$ tablet of buprenorphine as rescue medication per day from day 2 until the end of the study and who recorded at least satisfactory pain relief at each application of a new patch' (Sittl). ${ }^{31}$ The third study, on the contrary, used only the rescue therapy as the primary outcome, in terms of the number of buprenorphine SL tablets required each day. Bohme ${ }^{28}$ reported a percentage of responder patients of $34 \%$ for $35 \mu \mathrm{g} /$ hour, $37 \%$ with for $52.5 \mu \mathrm{g} / \mathrm{hour}$, and $50 \%$ for $70 \mu \mathrm{g} / \mathrm{hour}$, but these response rates failed to reach statistical significance. The proportion of patients reporting good to complete pain relief, none to mild pain on a verbal rating scale (VRS), and an uninterrupted sleep for more than 6 hours increased during the double-blind phase, but the authors do not report a test of statistical significance vs placebo. Overall, 23\% of the patients reported adverse events, with no statistically significant differences between the treatment groups. In the study by Sittl, ${ }^{31}$ the percentage of responders was very similar to that in the Bohme ${ }^{28}$ study (ie, $36.6 \%, 47.5 \%$, and $33.3 \%$ for the 3 dosages); also, in this case, the difference vs placebo failed to reach statistical significance in the $70 \mu \mathrm{g} /$ hour patch. Buprenorphine seemed to give better results than the placebo also in terms of rescue therapy $(P=0.002)$, pain relief, pain intensity, and duration of sleep uninterrupted by pain ( $P$ value not reported). The percentage of patients reporting at least 1 adverse event was high for both buprenorphine $(85.4 \%, 80.5 \%, 75.7 \%$ for the 3 patches) and placebo group (73.7\%) with no statistical difference. In the study by Sorge, ${ }^{32}$ the mean daily requirement of buprenorphine SL tablets during the double-blind phase was lower than that required during the run-in for the buprenorphine TDS group (-55.4\%, dose-dependent) than for placebo $(-45.1 \%, P=0.01)$, but was similar in terms of mean number of daily dose (in $\mathrm{mg}$ ) consumed ( 0.5 for all patients, 0.4 vs 0.6 for cancer patients). Pain intensity, pain relief, and sleep quality evaluation suggested a better effect of buprenorphine, although a statistical significance was not reached or it was not evaluated or reported. Adverse events were reported in $54.4 \%$ of the buprenorphine TDS group and $42.6 \%$ of the placebo group with no significant difference. Radbruch $^{29}$ reported the aggregated results of these 3 RCTs and classified the patients according to the disease: among the cancer patients, $36 \%$ of those with $35 \mu \mathrm{g} /$ hour patch and $42 \%$ and $40 \%$ of those with the 52.5 and $70 \mu \mathrm{g} /$ hour patch were classified as responders vs $23 \%$ of the placebo.

Likar $^{40}$ compared the efficacy and tolerability of the 2 different delivery schedules in subjects who have already responded to buprenorphine: patients (only 9 with cancer) were randomized to a treatment sequence in which they changed the buprenorphine patch every 3 days during the first step of the study (3-day regimen) or every 4 days (4-day regimen). In the second phase, the patients crossed over to the alternative regimen. The 2 regimens failed to show any statistical difference in terms of patient's and physician's satisfaction, pain intensity assessed with a numerical rating scale (NRS) (3.73 for 3-day regimen and 3.88 for 4-day regimen), pain relief, and tolerability. The latter findings were presented only in an aggregated way, making it impossible to evaluate the effect of the 2 interventions in cancer patients.

To date, the study by Pace ${ }^{42}$ is the only comparative trial available. It compared the effects of buprenorphine of $35 \mu \mathrm{g} /$ hour with the oral SR morphine of $60 \mathrm{mg} /$ day in an open-label study. The patients treated with transdermal buprenorphine experienced significantly greater improvement in pain intensity ( -2.5 for buprenorphine, -1.4 for morphine), quality of sleep, and quality of life. Adverse drug reactions (ADRs) were not reported and the side effects that were significantly more frequent for morphine than for buprenorphine, were vertigo, constipation, and nausea.

Finally, more recently, another RCT vs placebo was conducted to evaluate the maintenance of efficacy (Poulain) ${ }^{44}$ 
Table I List and characteristics of the 19 papers selected

\begin{tabular}{|c|c|c|c|c|c|}
\hline Reference & $\begin{array}{l}\text { Year of } \\
\text { publication }\end{array}$ & Country & Study design & $\begin{array}{l}\text { Total number } \\
\text { of patients } \\
\text { (cancer:non-cancer) }\end{array}$ & Remarks \\
\hline Böhme $^{28}$ & 2003 & $\begin{array}{l}\text { Austria, Germany } \\
\text { and Hungary }\end{array}$ & $\begin{array}{l}\text { Parallel double-blind } \\
\text { RCT vs placebo }\end{array}$ & $\begin{array}{l}15 \mid \\
(83: 68)\end{array}$ & \\
\hline Radbruch $^{29}$ & 2003 & Germany & $\begin{array}{l}3 \text { parallel double-blind } \\
\text { RCTs vs placebo }\end{array}$ & $\begin{array}{l}445 \\
(249: 196)\end{array}$ & $\begin{array}{l}\text { Collects information from other } \\
\text { studies }^{32,35,36}\end{array}$ \\
\hline Radbruch ${ }^{30}$ & 2003 & Germany & Observational & $\begin{array}{l}3255 \\
(846: 2409)\end{array}$ & $\begin{array}{l}\text { Preliminary data from another } \\
\text { study }^{37}\end{array}$ \\
\hline Sitt $\left.\right|^{31}$ & 2003 & $\begin{array}{l}\text { Austria, Germany } \\
\text { and The Netherlands }\end{array}$ & $\begin{array}{l}\text { Parallel double-blind } \\
\text { RCT vs placebo }\end{array}$ & $\begin{array}{l}157 \\
(121: 36)\end{array}$ & \\
\hline Sorge ${ }^{32}$ & 2004 & Germany and Poland & $\begin{array}{l}\text { Parallel double-blind } \\
\text { RCT vs placebo }\end{array}$ & $\begin{array}{l}137 \\
(45: 92)\end{array}$ & \\
\hline Griessinger $^{33}$ & 2005 & Germany & Observational & $\begin{array}{l}13179 \\
(3690: 9489)\end{array}$ & Post-marketing surveillance \\
\hline Muriel $^{34}$ & 2005 & Spain & Observational & $\begin{array}{l}1212 \\
(207: 1005)\end{array}$ & Open-label \\
\hline Apolone ${ }^{35}$ & 2006 & Italy & Observational & not reported & $\begin{array}{l}\text { Preliminary data from another } \\
\text { study }{ }^{50}\end{array}$ \\
\hline Likar ${ }^{36}$ & 2006 & $\begin{array}{l}\text { Austria, Germany, } \\
\text { Hungary, Poland } \\
\text { and The Netherlands }\end{array}$ & Observational & $\begin{array}{l}239 \\
(134: 105)\end{array}$ & $\begin{array}{l}\text { Long-term follow-up of patients } \\
\text { recruited in previous RCTs } s^{32,35,36}\end{array}$ \\
\hline Mercadante ${ }^{37}$ & 2006 & Italy & $\begin{array}{l}\text { Dose escalation feasibility } \\
\text { trial }\end{array}$ & 10 & $\begin{array}{l}\text { Describes the efficacy and } \\
\text { tolerability of a dosage increase } \\
\text { up to } 140 \mu \mathrm{g} / \text { hour }\end{array}$ \\
\hline Camba ${ }^{38}$ & 2007 & Spain & Observational & $\begin{array}{l}762 \\
(164: 598)\end{array}$ & \\
\hline Freye $^{39}$ & 2007 & Germany & Rotation feasibility trial & $\begin{array}{l}42 \\
(9: 33)\end{array}$ & $\begin{array}{l}\text { Describes the switch from } \\
\text { high-dose morphine to TDS } \\
\text { buprenorphine }\end{array}$ \\
\hline Likar $^{40}$ & 2007 & Austria & $\begin{array}{l}\text { Crossover open-label } \\
\text { RCT comparing } 2 \text { schemes }\end{array}$ & $\begin{array}{l}49 \\
(9: 40)\end{array}$ & $\begin{array}{l}\text { Compares the efficacy and } \\
\text { tolerability of } 3 \text {-day vs } 4 \text {-day } \\
\text { patch change schedule }\end{array}$ \\
\hline Mercadante $^{41}$ & 2007 & Italy & $\begin{array}{l}\text { Crossover non-randomized } \\
\text { clinical trial (vs fentanyl) }\end{array}$ & 22 & $\begin{array}{l}\text { Describes the switch from one } \\
\text { opioid to the other and then back } \\
\text { to the previous one }\end{array}$ \\
\hline Pace $^{42}$ & 2007 & Italy & $\begin{array}{l}\text { Parallel open-label } \\
\text { RCT vs morphine }\end{array}$ & 52 & \\
\hline Likar $^{43}$ & 2008 & Austria & Observational & $\begin{array}{l}82 \\
(6: 76)\end{array}$ & $\begin{array}{l}\text { Compares efficacy and tolerability } \\
\text { in different age groups }\end{array}$ \\
\hline Poulain ${ }^{44}$ & 2008 & $\begin{array}{l}\text { Austria, Belgium, } \\
\text { Croatia, France, Poland, } \\
\text { The Netherlands }\end{array}$ & $\begin{array}{l}\text { Parallel double-blind } \\
\text { RCT vs placebo }\end{array}$ & 189 & \\
\hline Wirz ${ }^{45}$ & 2008 & Germany & Observational & 174 & Random selection of patients \\
\hline Apolone ${ }^{46}$ & 2009 & Italy & Observational & 257 & Outcome research study \\
\hline
\end{tabular}

Abbreviations: RCT, randomized controlled trial; TDS, transdermal delivery system.

in severe cancer pain. Opioid-tolerant patients were converted to buprenorphine TDS during a run-in phase and then randomized for the 2-week maintenance phase; of the 289 patients initially recruited, only 189 entered the second phase, because 100 discontinued the treatment for adverse events or lack of efficacy. The primary efficacy outcome was the proportion of the responder patients (defined as patients completing at least 12 days of the double-blind period, with an average pain intensity score of $<5$ on the numerical rating scale during the last 6 days of treatment, and not using 


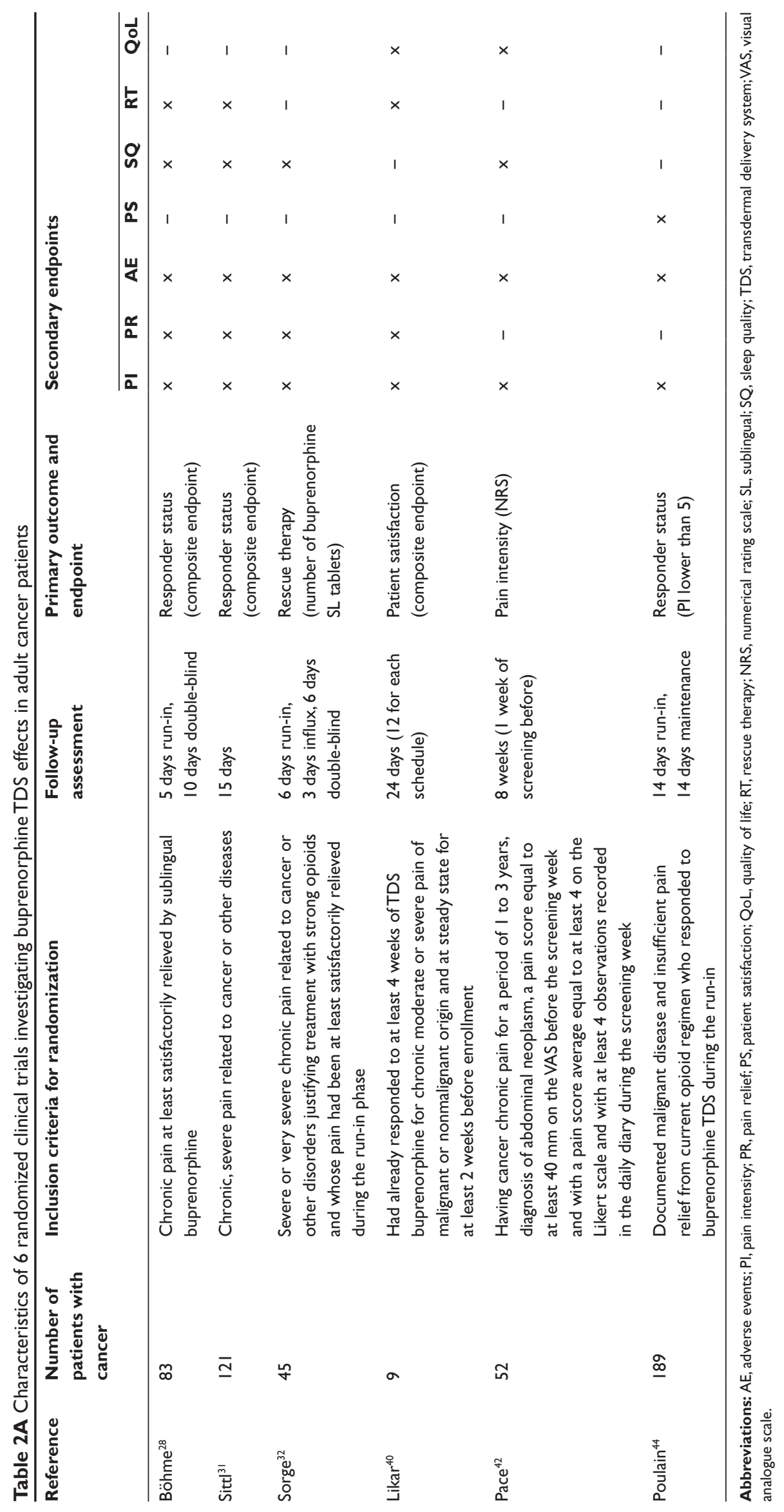




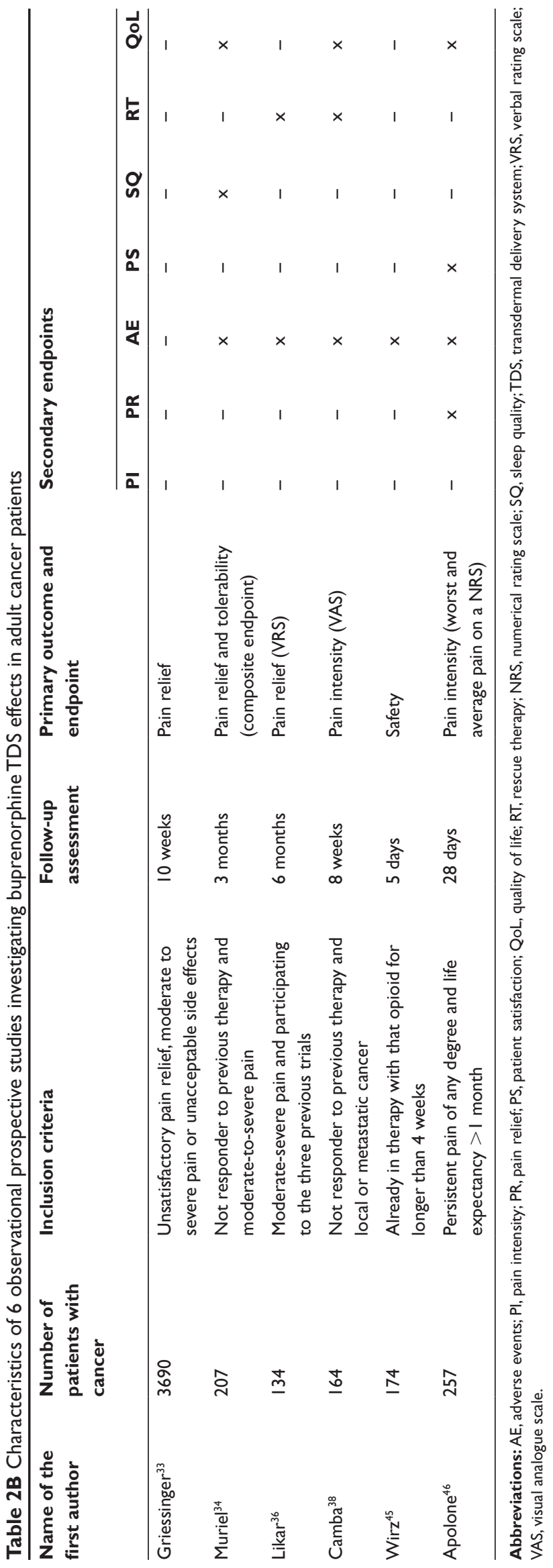

more than 2 tablets of rescue medication per day). More patients receiving transdermal buprenorphine of $70 \mu \mathrm{g} /$ hour responded (74.5\%) compared with those receiving placebo $(50 \%)(P=0.0003)$. Pain intensity was significantly lower in the TDS containing buprenorphine group (1.8) compared with placebo (2.7). In addition, the daily consumption of SL tablets remained stable during the double-blind phase for buprenorphine, but increased from 0.6 to 1.7 tablets for the placebo group. The incidence of adverse events was slightly higher for buprenorphine than for the placebo group, and the most commonly reported symptoms were nausea, vomiting, and constipation ( $P$ value not reported).

\section{Observational prospective studies}

The first observation prospective study was a post-marketing surveillance in Germany in 13,179 cancer and non-cancer patients with unsatisfactory pain relief or unacceptable side effects with previous therapy. ${ }^{33}$ Patients with cancer-related pain were about $30 \%$ of the total sample. Seventy percent of them started with $35 \mu \mathrm{g} /$ hour patch, $22 \%$ with $52.5 \mu \mathrm{g} /$ hour, and $7 \%$ with $70 \mu \mathrm{g}$ /hour; patch strength was changed at visit 1 (median 14 days) in 16\% of the patients and at visit 2 (median 40 days) in $2 \%$ of the subjects. 'Good' or 'very good' pain relief was obtained in $84 \%$ of the cancer patients. Twentyseven percent of the cancer patients experienced 1 adverse event (21.6\% experienced serious adverse events).

Muriel $^{34}$ in Spain followed up for 3 months the cancer and non-cancer patients who were beginning buprenorphine for moderate to severe pain who had not responded to nonopioid analgesics. Patients began buprenorphine TDS at the lowest possible dosage, and the daily median amount at the baseline was $35 \mu \mathrm{g} /$ hour (all the patients). At the end of the study, $22 \%$ of all the patients had been changed to a higher dosage. The study included 207 patients with cancer (17\%). Sixty-five percent of these reported 'good' or 'very good' pain relief after 1 month, and 57\% after 3 months. Other outcomes and adverse events were not reported for the cancer population alone: $63 \%$ of all the patients reported and improvement in the quality of sleep after 1 month, and 56\% after 3 months, and the quality of life also improved, from a mean EQ-5D score of 40.6 at baseline to 56.8 at the end of the study $(P<0.001) ; 42 \%$ of the patients experienced at least 1 adverse event during the follow-up.

Some patients recruited in the 3 registered clinical trials mentioned earlier, $28,31,32$ were subsequently included in a follow-up study (Likar) ${ }^{36}$ where they continued the treatment with $35 \mu \mathrm{g} /$ hour patch and SL tablets $(0.2 \mathrm{mg})$. There were 134 cancer patients who were followed up for a mean 
of 119 days, but 107 discontinued after the first 2 months, mainly because of death and insufficient pain relief. Among the cancer patients, $86.6 \%$ reported an 'at least satisfactory' pain relief throughout the study period. Eighty-four cancer patients reported adverse events; 31 events were probably drug-related and 26 were ADRs (the more frequent were nausea and vomiting).

$\mathrm{Camba}^{38}$ summarized 3 longitudinal multicentre studies conducted by the Sociedad Española del Dolor. The third study involved 164 cancer patients with moderate to severe pain, who did not respond to previous analgesics, and who were followed up for 8 weeks after the first administration of buprenorphine TDS. Fifteen percent of the patients started with $17.5 \mu \mathrm{g} /$ hour and $82 \%$ started with $35 \mu \mathrm{g} /$ hour of the drug. Mean pain intensity, measured with a visual analogue scale (VAS), at baseline was 7.4 and decreased to 3.2 at week $8(P<0.001)$. This study also included a quality of life questionnaire and parameters such as physical fitness, social and daily activities, and how they felt significantly improved during the course of the observation period. Fifty-one patients discontinued the study; the results of adverse events were not reported for the cancer study alone.

Wirz ${ }^{45}$ conducted a controlled trial with the oral sustainedrelease hydromorphone, transdermal fentanyl, and buprenorphine on randomly selected 174 cancer patients, to assess the difference in terms of gastrointestinal symptoms in long-term treatment (all patients were pretreated with their current opioid therapy for more than 28 days). Patients were selected for participation by random selection from a sample of outpatients undergoing pain therapy with one of the study medications. Apart from a significantly higher incidence of stool-free periods of $>72$ hour for transdermal opioids, there were no differences in the effects of the 3 drugs in terms of nausea, emesis, and constipation.

Apolone $^{46}$ followed up 1801 advanced cancer patients with persistent pain of any degree, using several outcomes and endpoints, including pain intensity measured with a NRS, satisfaction, and quality of life: among the patients recruited, 257 were consuming buprenorphine at baseline, with a mean TDS dose of $43.2 \mu \mathrm{g} /$ hour (median 35) and an average increase to 50.0 at day 28. All the outcome measures consistently improved over time, in terms of statistical significance and clinical relevance. For example, the worst pain differences were -1.4 points $(95 \%$ confidence interval $-1.1 /-1.8$, $P<0.0001)$. The effect-size estimates indicated that on average, the endpoints based on pain intensity were more responsive (range 0.2 to 0.6 ) than those measuring pain relief, satisfaction, or quality of life (range 0.2 to 0.3 ), and the best measure was worst pain difference. About 34\% of the patients had an improvement of at least 2 points in worst pain, nearly $48 \%$ improved less or were stable, $15 \%$ had a $20 \%$ improvement in pain relief, and $40 \%$ reported an increase in satisfaction. The most frequent side effects were constipation (56\%) and sedation $(51 \%)$, but the frequency of the symptoms rated by patients as 'a lot/very much' was always less than $25 \%$.

\section{Estimate of the overall treatment effect on pain}

When studies were evaluated according to the type of outcomes and endpoints used to find a measure to pool studies and estimate the overall treatment effect, a substantial heterogeneity emerged that did not allow statistical pooling.

In the 6 RCTs, 3 studies ${ }^{28,31,44}$ shared the same primary outcome (the responder status), an endpoint that may be considered valid and relevant in this setting, but it was actually operationally defined in different ways (mentioned previously). The other primary outcomes were rescue therapy, ${ }^{32}$ patient satisfaction, ${ }^{40}$ and pain intensity. ${ }^{42}$ When we expanded this assessment to the secondary outcomes, among the wide list of measures used (from indicators of pain intensity to safety and quality of life), the only one used in all 6 RCTs was pain intensity, which became our candidate for a formal attempt for a statistical combination.

In the 6 observational studies, the same evaluation again yielded a very heterogeneous result: in 3 cases the primary endpoint was pain relief, ${ }^{33,34,36}$ in 2 it was pain intensity, ${ }^{38,46}$ and in 1 it was safety. ${ }^{45}$

As 8 studies, 6 clinical trials $28,31,32,40,42,44$ and 2 observational studies, ${ }^{38,46}$ have used patients' reported pain intensity, we focused on this subsample. Table 3 presents the details of the studies that were candidates for a pooling analysis.

A deeper analysis of the studies' characteristics and efficacy estimates reported in the papers showed that in this subsample also, the type of data was not appropriate for combining the results. For example, although all the studies used some standardized measures of pain intensity, the assessment tools were different: in 4 cases NRS was used, ${ }^{40,42,44,46}$ in 3 cases VRS was used, ${ }^{28,31,35}$ and in 1 case VAS was used. ${ }^{38}$ In addition, for NRS different anchors were actually used to identify the least and worst pain intensity. In 4 cases $^{28,31,32,40}$ it was not possible to distinguish the results between cancer and non-cancer patients. Finally, the period of time chosen by the authors to estimate the difference of pain intensity attributable to the intervention varied from $10^{28,32}$ to 56 days. ${ }^{38}$ 
Table 3 Description of pain intensity outcomes and endpoints in 6 randomized clinical trials and 2 prospective observational studies investigating buprenorphine TDS effects in adult cancer patients

\begin{tabular}{|c|c|c|c|c|c|c|}
\hline Reference & Primary outcome & $\begin{array}{l}\text { Pain intensity } \\
\text { measure }\end{array}$ & Details of the pain scale & $\begin{array}{l}\text { Mean pain at } \\
\text { baseline for cancer } \\
\text { patients (sd) }\end{array}$ & $\begin{array}{l}\text { Mean pain after } \\
\text { treatment (sd) }\end{array}$ & $\begin{array}{l}\text { Assessment } \\
\text { time (days) }\end{array}$ \\
\hline Böhme $^{28}$ & Responder status & 5-point (VRS) & $\begin{array}{l}\text { Very severe, severe, } \\
\text { moderate, slight, absent }\end{array}$ & not reported & not reported & 10 \\
\hline Sitt $\left.\right|^{31}$ & Responder status & 5-point (VRS) & $\begin{array}{l}\text { Very severe, severe, } \\
\text { moderate, slight, absent }\end{array}$ & not reported & not reported & 15 \\
\hline Sorge ${ }^{32}$ & $\begin{array}{l}\text { Number of BP SL } \\
\text { tablets required as } \\
\text { rescue therapy }\end{array}$ & 5-point (VRS) & $\begin{array}{l}\text { Very severe, severe, } \\
\text { moderate, slight, absent }\end{array}$ & not reported & not reported & 10 \\
\hline Likar $^{40}$ & $\begin{array}{l}\text { Patient satisfaction } \\
\text { with treatment }\end{array}$ & $\begin{array}{l}\text { II-point (NRS) } \\
\text { MPQ }\end{array}$ & $\begin{array}{l}\text { No pain- worst pain } \\
\text { imaginable I } 5 \text { items then } \\
\text { categorized } 0 \text { (no pain) to } \\
3 \text { (worst pain imaginable) }\end{array}$ & not reported & not reported & 12 \\
\hline \multirow[t]{2}{*}{ Pace $^{42}$} & Pain severity & II-point (NRS) & $\begin{array}{l}0=\text { no pain; } 10=\text { maximum } \\
\text { possible pain }\end{array}$ & $6.4(0.2)$ & $3.9(0.3)$ & 56 \\
\hline & & SF-MPQ (VAS) & $\begin{array}{l}\text { I } 5 \text { items for pain in the last } \\
\text { week then categorized } \\
0 \text { (no pain) to } 3 \text { (acute pain) }\end{array}$ & $67.7(2.1)$ & $36.9(1.2)$ & \\
\hline Poulain ${ }^{44}$ & Responder status & II-point (NRS) & $\begin{array}{l}\text { No pain to pain as bad you } \\
\text { can imagine }\end{array}$ & $1.5(1.5)$ & $\mathrm{I} .5(\mathrm{I} .5)$ & 14 \\
\hline Camba ${ }^{38}$ & Pain intensity & VAS & $\begin{array}{l}0 \mathrm{~cm}=\text { no pain to } \\
10 \mathrm{~cm}=\text { maximum pain }\end{array}$ & $7.4(1.2)$ & 3.2 (not reported) & 56 \\
\hline Apolone ${ }^{46}$ & $\begin{array}{l}\text { Worst and average } \\
\text { pain intensity }\end{array}$ & II-point (NRS) & $\begin{array}{l}\text { No pain to pain as bad you } \\
\text { can imagine Worst, actual, } \\
\text { least and average pain }\end{array}$ & $\begin{array}{l}6.4(2.3) \text { worst } \\
3.2(2.6) \text { actual }\end{array}$ & $\begin{array}{l}4.8(2.5) \text { worst } \\
2.3(2.2) \text { actual }\end{array}$ & 28 \\
\hline
\end{tabular}

Abbreviations: NRS, numerical rating scale; VRS, verbal rating scale; VAS, visual analog scale; SF-MPQ, Short-form McGill Pain Questionnaire.

\section{Estimate of overall safety and tolerability}

After the narrative description of safety and tolerability given for each paper and study, we tried to summarize and integrate these important characteristics; however, papers describing the 12 clinical studies reported the safety and tolerability of the drugs under evaluation using different and heterogeneous methods and terms. Most authors reported side effects in terms of adverse events, ADR, or simply using a list of most frequent symptoms reported by patients. Sometimes, adverse events and ADR were also classified as severe. Some authors reported side effects that were attributable to opioid administration only, while others classified them according to the system or organ involved, such as skin, central nervous system, or according to the type, such as nausea, vomiting, and constipation. Given the large variability of the methods used, we tried to classify them into the following groups: adverse events, ADR, gastrointestinal (including nausea, vomiting, constipation), central nervous system (including confusion, dizziness), and skin (including pruritus and local erythema). Table 4 shows the results of such reclassification and synthesis. Most of the times, it was not possible to identify the exact quantity and type of the side effects, as the authors did not report the estimates according to the type of patients (cancer vs non-cancer). In addition, the unit of analysis was not homogeneous across the studies (as the authors reported either the number of events or the number of patients with at least 1 event), yielding a quite unreliable classification of the phenomenon.

\section{Discussion}

Buprenorphine TDS has been available in most European countries since 2002, to treat moderate to severe chronic pain. The TDS formulation that allows for a slow release by minimizing the typical opioid side effects makes it a good alternative to the other oral opioids in clinical practice. The results from 3 clinical pivotal trials ${ }^{28,31,32}$ including only 453 cancer patients, documented its analgesic efficacy, at least in terms of the responders' status, and the safety profile that was typically opioid in nature and not different from placebo in terms of incidence of reported events; local adverse events associated with TDS application were erythema and pruritus, while the most frequent systemic 
adverse events were nausea and vomiting. Pharmacokinetics and pharmacodynamics data suggest that buprenorphine TDS may be safely used in aged patients and in renally impaired individuals, although the small sample size of the studies and the restriction in inclusion criteria did not allow any subgroup or interaction analysis. Post-marketing and outcome research of the prospective studies yielded satisfactory results in terms of effectiveness, despite the presence of a large variability in inclusion/exclusion criteria and outcomes assessment. Safety and tolerability results were often reported together for both cancer and non-cancer patients, making it difficult to extract and summarize the findings across the individual original studies. Despite these limitations, the type of adverse events was in line with that expected, given the opioid nature of the drug, and the reported incidence from observational studies, when evaluable, was low, mostly in terms of serious events.

The evidence for comparative efficacy and safety is indeed scanty, as most of the efficacy data are from placebo trials. Only one $\mathrm{RCT}^{42}$ was designed to compare it with morphine. This trial had an open-label design and a very small sample size. As pointed out by other researchers, ${ }^{9}$ well-designed and statistically powered controlled clinical trials focusing exclusively on treating cancer patients suffering from pain using buprenorphine TDS are still lacking. In addition, our analysis based on a systematic review that included published papers up to April 2009 confirmed that the quality of the 19 reports describing 16 studies was poor and did not allow for safe data pooling. Studies, although stratified according to the study design, were very heterogeneous in terms of population included, interventions studied, comparators evaluated, and outcomes assessed. Even when the same outcome was formally assessed (eg, the responders' status or the patients' reported pain intensity), the differences in terms of operational definition of endpoints, timing of the assessment, or simply the type of measures used (NRS vs VRS vs VAS), made it impossible to identify a subsample for formal data synthesis and statistical pooling.

The results of this systematic review confirm the potential of this drug when delivered through a TDS, but it may be considered as a lost opportunity for a meta-analysis. The studies that we retrieved were very few, very heterogeneous, and reported results in a way that prevented an appropriate data extraction and data pooling. This fact might explain why TDS buprenorphine has not yet been recommended by national and international guidelines, and sometimes is not included in the list of reimbursable drugs at national or local levels.

In fact, the poor quality of pain studies is a wellknown phenomenon throughout the field, across the type of interventions, countries, and clinical settings. A recent literature review carried out by the European Palliative Care Research Collaborative Group to assess the quality of pain assessment in palliative care documented that in the 230 papers retrieved and evaluated, the methods and tools

Table 4 Local and systemic safety and tolerability adverse events and adverse drug reactions from 12 selected studies

\begin{tabular}{|c|c|c|c|c|c|c|}
\hline \multirow[t]{2}{*}{$\begin{array}{l}\text { Name of the first } \\
\text { author }\end{array}$} & \multirow[t]{2}{*}{$\begin{array}{l}\text { Number of patients } \\
\text { with cancer }\end{array}$} & \multirow[t]{2}{*}{ Number of AEs } & \multirow[t]{2}{*}{ Number of ADRs } & \multicolumn{3}{|c|}{$\begin{array}{l}\% \text { of patients reporting side } \\
\text { effects or AEs related to }\end{array}$} \\
\hline & & & & $\overline{\mathbf{G I}}$ & CNS & Skin \\
\hline Böhme ${ }^{28}$ & 83 & NA & NA & NA & NA & NA \\
\hline Sitt $\left.\right|^{31}$ & 21 & NA & 6 & NA & NA & NA \\
\hline Sorge ${ }^{32}$ & 45 & NA & NA & NA & NA & NA \\
\hline Likar $^{40}$ & 9 & NA & 0 & NA & NA & NA \\
\hline \multirow[t]{2}{*}{$\mathrm{Pace}^{42}$} & 52 & I5/26 TDS buprenorphine & 0 & 19.2 & 38.4 & NA \\
\hline & & $37 / 26$ oral morphine & & 73.0 & 69.2 & \\
\hline \multirow[t]{2}{*}{ Poulain $^{44}$} & 89 & NA & 2 & 18.0 & 4.8 & NA \\
\hline & & & & 15.8 & 0.0 & \\
\hline Griessinger $^{33}$ & 3690 & NA & 18 & NA & NA & NA \\
\hline Murie $^{34}$ & 207 & NA & NA & NA & NA & NA \\
\hline Likar $^{36}$ & 134 & 84 & 26 & 14.1 & 5.9 & 8.9 \\
\hline $\mathrm{Camba}^{38}$ & 164 & NA & NA & NA & NA & NA \\
\hline Wirz $^{45}$ & 174 & NA & NA & NA & NA & NA \\
\hline Apolone ${ }^{46, a}$ & 257 & NA & $25 \%$ & 33.5 & 25.4 & 2.5 \\
\hline
\end{tabular}

aln this study side effects were reported as 'opioids related symptoms' rated by patients as 'a lot/very much' impact.

Abbreviations: AE, adverse event; ADR, adverse drug reaction; GI, gastrointestinal; CNS, central nervous system; NA, not available; TDS, transdermal delivery system. 
used were very heterogeneous and did not meet the criteria identified by experts as minimal standards. ${ }^{47,48}$

In conclusion, buprenorphine TDS has been observed to have good intrinsic (pharmacological) characteristics and promising clinical results, suggesting the need to appropriately review the evidence base for its utility. The results from this systematic literature review are not conclusive and suggest the need for 3 sequential initiatives: 1) a meta-analysis carried out on individual data to minimize the problems that we have found working on aggregated data; 2) an international initiative to find a consensus on definitions, methods, and measures of pain assessment in clinical research; and 3) a well-designed, large, multicenter, international comparative study to produce final evidence about the relative effectiveness and safety of the available third-level WHO opioids. These above-mentioned actions are are now being planned.

For the Cochrane Collaboration, one group has published a protocol titled 'Buprenorphine for cancer pain'. The authors planned to carry out a systematic review based on an electronic search of 5 databases, including the contact of the original authors of the primary studies for clarification, or to obtain missing information or individual data. ${ }^{49}$

A joint initiative of 3 non-profit organizations (Center for the Research and Evaluation of Pain, Norwegian University of Science and Technology, Italian National Cancer Institute) planned an expert panel meeting on the issues related to cancer-pain assessment in clinical research. The first meeting involving experts from the USA and Europe, including representatives of FDA and EMEA, will be held in Milan, Italy, in September 2009.

Finally, on the basis of the results of this review and according to the preliminary results of a prospective outcome research study carried out in Italy on 1800 cancer patients with pain, ${ }^{50}$ a multicenter RCT to compare the efficacy of 4 strong opioids on cancer pain (buprenorphine, morphine, fentanyl, and oxycodone) will be launched at the end of this year, involving about 80 centers and 1000 patients.

\section{Disclosures}

Dr Apolone and Dr Corli have received consulting and lecture fees from Grunenthal-Italy.

\section{References}

1. Hearn J, Higginson IJ. Cancer pain epidemiology: a systematic review. In: Bruera ED, Portenoy RK, editors. Cancer Pain, Assessment and Management. Cambridge: Cambridge University Press; 2003.

2. van den Beuken-van Everdingen MH, de Rijke JM, Kessels AG, Schouten HC, van Kleef M, Patijn J. Prevalence of pain in patients with cancer: a systematic review of the past 40 years. Ann Oncol. 2007; 18:1437-1449.
3. Deandrea S, Montanari M, Moja L, Apolone G. Prevalence of undertreatment in cancer pain. A review of published literature. Ann Oncol. 2008;19:1985-1991.

4. World Health Organization. Cancer Pain Relief. 2nd ed. Geneva: W.H.O; 1996.

5. Jacox A, Carr DB, Payne R. New clinical-practice guidelines for the management of pain in patients with cancer. $N$ Engl J Med. 1994;330:651-655.

6. SIGN: Scottish intercollegiate guideline network. Control of pain in patients with cancer. A national clinical guideline. SIGN publication number 44, June 2000.

7. Hanks G, De Conno F, Cherny N, et al; for Expert Working Group of the Research Network of the European Association for Palliative Care. Morphine and alternative opioids in cancer pain the EAPC recommendations. Br J Cancer. 2001;84:587-593.

8. Skaer TL. Transdermal opioids for cancer pain. Health Qual Life Outcomes. 2006;31:4-24.

9. Kress HG. Clinical update on the pharmacology, efficacy and safety of transdermal buprenorphine. Eur J Pain. 2009;13:219-230.

10. McQuay HJ, Moore RA. Buprenorphine kinetics in humans. In: Cowan A, Lewis JW, editors. Buprenorphine: Combating Drug Abuse with a Unique Opioid. New York: Wiley-Liss; 1995:137-147.

11. Weinberg DS, Inturrisi CE, Reidembreg B, et al. Sublingual absorption of selected opioid analgesics. Clin Pharmacol Ther. 1988;44: 335-342.

12. Garrett ER, Chandran VR. Pharmacokinetics of morphine and its surrogates: bioanalysis, solvolysis kinetics, solubility, $\mathrm{pKa}$ values and protein binding of buprenorphine. J Pharmaceut Sci. 1985;74:515-524.

13. Huang P, Kehner GB, Cowan A, et al. Comparison of pharmacological activities of buprenorphine and norbuprenorphine: norbuprenorphine is a potent opioid agonist. J Pharmacol Exp Ther. 2001;297:688-695.

14. Cowan A. update on the general pharmacology of buprenorphine. In: Cowan A, Lewis JW, editors. Buprenorphine: Combating Drug Abuse with a Unique Opioid. New York: Wiley-Liss; 1995:31-47.

15. Traynor JR, Nahorski SR. modulation by mu-opioid agonists of guanosine-5'-0-(3-( ${ }^{35}$ S)thio)triphosphate binding to membranes from human neuroblastoma SH-SY5Y cells. Mol Pharmacol. 1995;47:848-854.

16. Selley DA, Liu Q, Childers SR. Signal transduction correlates of mu-opioid agonist intrinsic efficacy: receptor-stimulated [35S]GTP gamma $\mathrm{S}$ binding in $\mathrm{mMOR}-\mathrm{CHO}$ cells and rat thalamus. J Pharmacol Exp Ther. 1998;285:496-505.

17. Toll L, Berzetei-Gurske IP, Polgar WE, et al. Standard binding and functional assays related to medications development division testing for potential cocaine and opiate narcotic treatment medications. NIDA Res Monogr. 1998;178:440-466.

18. Lee K, Akil H, Woods JH, et al. Novel binding properties of oripavines at a cloned mu-opioid receptor. Eur J Pharmacol. 1999;378: 323-330.

19. Romero DV, Partilla JS, Zheng QX, et al. Opioid peptide receptor studies. Buprenorphine is a potent and selective mu/kappa antagonist in the [35S]-GTP-gamma-S functional binding assay. Synapse. 1999;34:83-94.

20. Zhu J, Luo LY, Chen C, et al. Activation of the cloned human kappa opioid receptor by agonists enhances [35S]GTPgammaS binding to membranes: determination of potencies and efficacies of ligands. J Pharmacol Exp Ther. 1997;282:676-684.

21. Dahan A, Yassen A, Romberg R, et al. Buprenorphine induces ceiling in respiratory depression but not in analgesia. Br J Anaesth. 2006;96:627-632.

22. Rothman RB. Buprenorphine: a review of the binding literature. In: Cowan A, Lewis JW, editors. Buprenorphine: Combating Drug Abuse with a Unique Opioid. New York: Wiley-Liss; 1995. p. 19-29.

23. Villiger JW, Taylor KM. Buprenorphine: characteristics of binding sites in the rat central nervous system. Life Sci. 1981;29:2699-2708.

24. Sidhu BS, Khichy S, Singh KH. Comparative evaluation of intramuscular buprenorphine, pentazocine and nefopam in postoperative pain relief. J Ind Med Assoc. 1993;91:288-289. 
25. Evans HC, Easthoper SE. Transdermal buprenorphine. Drugs. 2003;63:1999-2010.

26. Johnson RE, Fuadala PJ, Payne R. Buprenorphine: considerations for pain management. J Pain Symptom Manage. 2005;29:297-396.

27. Higgins JPT, Green S, editors. Cochrane Handbook for Systematic Reviews of Interventions Version 5.0.0 [updated February 2008]. The Cochrane Collaboration, 2008.

28. Böhme K, Likar R. Efficacy and tolerability of a new opioid analgesic formulation, buprenorphine transdermal therapeutic system (TDS) in the treatment of patients with chronic pain. A randomized, double-blind, placebo-controlled study. Pain Clinic. 2003;15:193-202.

29. Radbruch L, Vielvoye-Kerkmeer A. Buprenorphine TDS: the clinical development- rationale and results. J Clin Pract Suppl. 2003;133:15-28.

30. Radbruch L. Buprenorphine TDS: use in daily practice, benefits for patients. Int J Clin Pract Suppl. 2003;133:19-22.

31. Sittl R, Griessinger N, Likar R, Analgesic efficacy and tolerability of transdermal buprenorphine in patients with inadequately controlled chronic pain related to cancer and other disorders: a multicenter, randomized, double-blind, placebo-controlled trial. Clin Ther. 2003;25:150-168.

32. Sorge J, Sittl R. Transdermal buprenorphine in the treatment of chronic pain: results of a Phase III, multicenter, randomized, double-blind, placebo-controlled study. Clin Ther. 2004;26:1808-1820.

33. Griessinger N, Sittl R, Likar R. Transdermal buprenorphine in clinical practice- post-marketing surveillance study of 13,179 patients. Curr Med Res Opin. 2005;21:1147-1156.

34. Muriel C, Failde I, Micò JA, Neira M, Sanchez-Magro I. Effectiveness and tolerability of the buprenorphine transdermal system in patients with moderate to severe chronic pain: a multicenter, open-label, uncontrolled, prospective, observational clinical study. Clin Ther. 2005;27:451-462.

35. Apolone G, Mangano S, Compagnoni A, et al; for Cancer Pain Outcome Research Group. A multidisciplinary project to improve the quality of cancer pain management in Italy. J Ambulatory Care Manage. 2006;29:332-341.

36. Likar R, Kayser H, Sittl R. Long-term management of chronic pain with transdermal buprenorphine: a multicenter, open-label, follow-up study in patients from three short-term clinical trials. Clin Ther. 2006;28: 943-952.

37. Mercadante S, Ferrera P, Villari P. Is there a ceiling effect of transdermal buprenorphine? Preliminary data in cancer patients. Support Care Cancer. 2007;15:441-444.

38. Camba M, Rodriguez-Lopez MJ, Muriel C. Buprenorphine TDS in the treatment of chronic nociceptive, neuropathic and cancer-related pain. J Appl Ther Res. 2007;6:3-13.
39. Freye E, Anderson-Hillemacher A, Ritzdorf I, Levy JV. Opioid rotation from high-dose morphine to transdermal buprenorphine $\left(\right.$ Transtec $\left.^{\mathbb{1}}\right)$ in chronic pain patients. Pain Practice. 2007;7:123-129.

40. Likar R, Lorenz V, Korak-Leite M, Kager I, Sittl R. Transdermal buprenorphine patches applied in a 4-day regimen versus 3-day regimen: a single-site, phase III, randomized, open-label, crossover comparison. Clin Ther. 2007;29:1591-1606.

41. Mercadante S, Porzio G, Fulfaro F, et al. Switching from transdermal drugs: an observational " $\mathrm{N}$ of 1" study of fentanyl and burenorphine. J Pain Symptom Manage. 2007;532-538.

42. Pace MC, Passavanti MB, Grella E, et al. Buprenorphine in longterm control of chronic pain in cancer pain. Front Biosci. 2007;12: $1291-1299$.

43. Likar R, Vadlau EM, Breschan C, Kager I, Korak-Leiter M, Ziervogel G. Comparable analgesic efficacy of transdermal buprenorphine in patients over and under 65 years of age. Clin J Pain. 2008;24:536-543.

44. Poulain P, Denier W, Douma J, et al. Efficacy and safety of transdermal buprenorphine: a randomized, placebo-controlled trial in 289 patients with severe cancer pain. J Pain Symptom Manage. 2008;36: $117-125$.

45. Wirz S, Wittmann M, Schenk M, et al. Gastrointestinal symptoms under opioid therapy: a prospective comparison of oral-sustained release hydromorphone, transdermal fentanyl, and transdermal buprenorphine. Eur J Pain. 2008; DOI:10.1016/j.ejpain.2008.09.005.

46. Apolone G, Corli O, Negri E, Mangano S, Montanari M, Greco MT; on behalf of the writing protocol committee and the Cancer Pain Outcome Research Study Group (CPOR SG) Investigators. Effects of transdermal buprenorphine on patients-reported outcomes in cancer patients. Results from the Cancer Pain Outcome Research (CPOR) Study Group. Clin J Pain. In press. 2009.

47. Hjermstad MJ, Gibbins J, Haugen DF, Caraceni A, Loge JH, Kaasa S; for EPCRC, European Palliative Care Research Collaborative. Pain assessment tools in palliative care: an urgent need for consensus. Palliat Med. 2008;22:895-903.

48. Kaasa S, Loge JH, Fayers P, et al. Symptom assessment in palliative care: a need for international collaboration. J Clin Oncol. 2008;26: 3867-3873.

49. Zeppetella G, Wiffen PJ. Buprenorphine for cancer pain. Cochrane Database of Systematic Reviews 2007, Issue 4. Art. No: CD006766. DOI: 10.1002/14651858.CD006766.

50. Apolone G, Corli O, Caraceni A, et al; for Cancer Pain Outcome Research Study Group (CPOR SG) Investigators. Pattern and quality of care of cancer pain management. Results from the Cancer Pain Outcome Research Study Group (CPOR SG). Br J Cancer. 2009;100: $1566-1574$
Therapeutics and Clinical Risk Management

\section{Publish your work in this journal}

Therapeutics and Clinical Risk Management is an international, peerreviewed journal of clinical therapeutics and risk management, focusing on concise rapid reporting of clinical studies in all therapeutic areas, outcomes, safety, and programs for the effective, safe, and sustained use of medicines. This journal is indexed on PubMed Central, CAS,

\section{Dovepress}

EMBase, Scopus and the Elsevier Bibliographic databases. The manuscript management system is completely online and includes a very quick and fair peer-review system, which is all easy to use. Visit http://www.dovepress.com/testimonials.php to read real quotes from published authors. 